Article

\title{
Forced Combustion Characteristics Related to Different Injection Locations in Unheated Supersonic Flow
}

\author{
Chae-Hyoung Kim ${ }^{1, *}$ and In-Seuck Jeung ${ }^{2}$ \\ 1 Engine Test and Evaluation Team, Korea Aerospace Research Institute, Daejeon 34133, Korea \\ 2 Department of Mechanical and Aerospace Engineering, Seoul National University, Seoul 08826, Korea; \\ enjis@snu.ac.kr \\ * Correspondence: avalonkc@kari.re.kr; Tel.: +82-102-1040-074
}

Received: 15 April 2019; Accepted: 29 April 2019; Published: 8 May 2019

\begin{abstract}
This work focuses on forced combustion with regards to the relationship between vent mixer models and several injection locations in unheated supersonic flow. A plasma jet torch was used to ignite the hydrogen-air mixture in a laboratory-scaled combustor duct. The flow field of the combustion was visualized with pressure and gas-sampling measurements. The vent mixers indicate good dispersion characteristics of the mixture for both parallel and normal 1 injections. However, forced combustion is dominantly governed by the injection rate toward the plasma jet (hot source) because the combustible region is restricted under the cold main flow. For this reason, the parallel injection, which provides the hydrogen-air mixture directly toward the plasma jet, shows good combustion performance. The normal 1 injection interacted with the vent mixers and shows slightly good combustion performance. Lastly, the normal 2 injection is little affected by the vent mixers and has poor combustion performance.
\end{abstract}

Keywords: supersonic combustion; vent mixer; mixing; combustion performance

\section{Introduction}

Hypersonic vehicle concepts for high-altitude passenger planes or space launchers have been designed based on dual-mode scramjet engines or rocket-based combined cycle (RBCC) engines [1,2]. These hypersonic vehicles are initially accelerated by the rocket booster to obtain the sufficient inflow air speed required for start-up of the scramjet engines. Before the scramjet engines operate, the inflow air into the combustor changes from subsonic to supersonic flow, which is called dual-mode. Dual-mode scramjet engines start from a flight Mach number of 2 with shock trains in the isolator [1]. When the flight Mach number goes beyond 5, the combustion mode changes to the supersonic combustion (or scramjet) mode. Under this transition mode, the isolator is generally used to prevent the shock train from affecting the intake of the vehicle [3].

For supersonic combustion, it is necessary for some mixers to hold the flame and to blend the fuel-air mixture in the supersonic flow [4]. These mixers are generally categorized into two types: passive methods and active methods. Passive methods, such as a cavity [5] and a step [6,7], provide a space to hold the fuel-air mixture with minimum flow disturbance to the supersonic flow. Of these, the step mixer is often chosen as the passive mixing device due to its simple geometric structure. However, the recirculation region generated behind a step mixer is considered to be a dead region [6]. Although there is a circular flow in the recirculation region, it is not sufficient to stir the fuel-air mixture. Furthermore, even though several injectors are equipped to actively inject fuel into the recirculation region, mixing enhancement has not been observed in past studies [7]. The active methods induce 
aerodynamic fluctuation to enhance mixing. For instance, Helmholtz resonators [8] create an acoustic wave and hyper mixers $[9,10]$ generate stream-wise vortices by a pressure gradient.

From these mixer models, to enhance mixing in the supersonic combustor, it is considered that a subsonic recirculation region is essential for an active stirring system. It is adequate to select the step mixer for a duct-type combustor to develop a new mixer associated with the concept. Moreover, for the dual-mode scramjet, the upstream area of the step mixer is the isolator and the enlarged downstream duct is used as the combustor. An air blowing device is applied to the step mixer to actively provide air into the recirculation region behind the step mixer. This new mixer is named the vent slot mixer, and this has been already studied in previous work [11,12]. The detailed design is discussed later in this paper.

In the previous work [12], the inflowing air through the slot enlarges the jet plume developed by the normal injection. The relationship between the vent mixer and the normal injection position has an effect on the mixing performance. In addition, the position of the injectors in the recirculation region is an important factor because the fuel (injectant) remnant is dependent on the injection direction in the recirculation region [13]. Because of this, several injectors were installed in different locations of the recirculation region in the current work. The previous work $[12,13]$ utilized the slot to supply air into the recirculation region, but the current work considers the difference between the mixing and combustion performances according to the usage of the slot and circular holes.

\section{Materials and Methods}

The rectangular duct-type supersonic combustor model was composed of a Mach 2 half nozzle and a discontinuous rectangular duct, as shown in Figure 1. The isolator was $50 \mathrm{~mm}$ long and $30.7 \mathrm{~mm}$ high, and the combustor was $210 \mathrm{~mm}$ long and $36.7 \mathrm{~mm}$ high. The pressure ratio between the isolator inlet and outlet was 2:1 and designed using Billig's formula [3]. Air in the laboratory room was drawn into a vacuum tank of $5 \mathrm{kPa}$ and then accelerated through the Mach 2 half nozzle. The unit Reynolds number of the mixer model was about $6.6 \times 10^{5}$ per meter. Hydrogen gas was used as an injectant. There were three injectors: a parallel injector (P), a normal 1 injector (N1), and a normal 2 injector (N2). A detailed description of these injectors is shown in Figure 1.

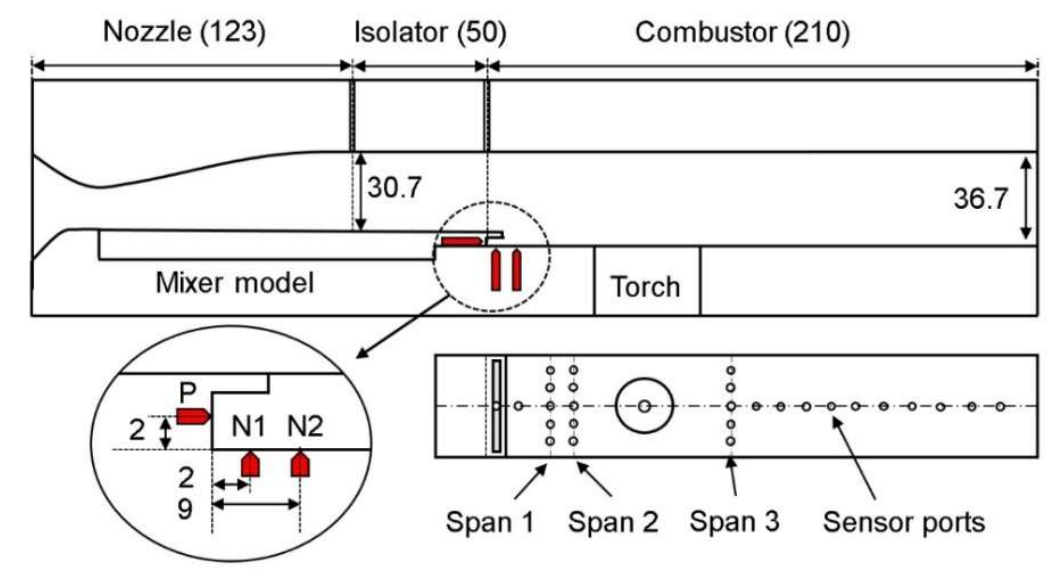

Figure 1. A rectangular duct-type supersonic combustor model (unit: $\mathrm{mm}$ ): P-Parallel injector, N1-Normal 1 injector, N2-Normal 2 injector.

The mixer models were attached to the lower wall. Two new mixer models were employed; one was a vent slot mixer (VSM), and the other was a vent circle mixer (VCM). The step mixer is generally chosen as the mixer model for a supersonic combustor owing to its simple structure, however, it has poor mixing performance in the recirculation region behind it. To enhance the mixing performance, the vent mixer was developed to actively provide air into the recirculation region behind the step mixer. The configuration of the vent mixers is shown in Figure 2. The vent mixer had an extended block from the step wall, which was $6 \mathrm{~mm}$ long and $2 \mathrm{~mm}$ thick. To supply the main air into the recirculation 
region, a slot or several circular holes were perforated in the extended block. The VSM had a slot and the VCM had circular holes, and these are detailed in Figure 2. The slot and circular holes were selected to compare the difference between the two-dimensional inflow of the slot and three-dimensional inflow of the circular holes in the recirculation region.

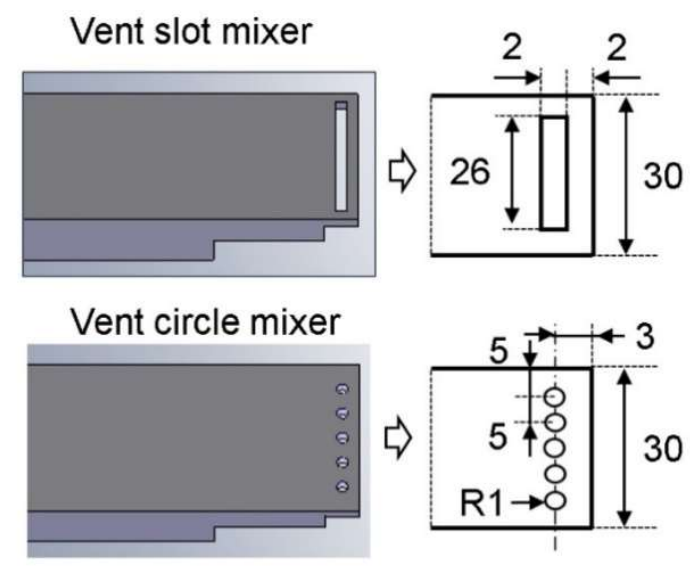

Figure 2. Mixer models: vent slot mixer and vent circle mixer.

The igniter and measurement methods in the current test were utilized under the same conditions of the previous tests $[7,11,12]$. A plasma jet (PJ) torch was used as the heat source to ignite the hydrogen [14]. The PJ was injected from a $1.5 \mathrm{~mm}$ diameter hole, which was placed at $60 \mathrm{~mm}$ from the mixer wall, with a power of $2.5 \mathrm{~kW}$ [15]. Schlieren images were captured using a stroboscope lamp with a pulse time of $180 \mathrm{~ns}$ and a digital camera (Canon EOS-D30), and then the original images were processed with the unsharp mask filter of Adobe Photoshop CS. Static pressures on the wall were recorded by strain-gauge type pressure transducers (PDCR23D-200psi, Scanivalve Inc., Liberty Lake, WA, USA) with a frequency of $10 \mathrm{~Hz}$. The injection pressure was measured by a PAB-A200KP pressure transducer (Kyowa Inc., New York, NY, USA). A gas-sampling technique was carried out to measure the residual gas on the lower wall through the pressure ports. The sample gas was evacuated to a small gas-sampling chamber of $0.4 \mathrm{kPa}$ for $10 \mathrm{~s}$ after each run, and it was analyzed with a Micro-GC analyzer (CP-4900, Varian Inc., Palo Alto, CA, USA). The gas-sampling uncertainty was less than $1 \%$ for $\mathrm{N}_{2}$ and $6 \%$ for $\mathrm{O}_{2}$ and $\mathrm{H}_{2}$.

\section{Results and Discussion}

The step mixer has a simple structure to hold the recirculation region behind it, but there is little stirring in this recirculation region. The upstream flow is separated at the edge of the step, and then the flow path is expanded, inducing an expansion fan and shear layer downstream, as shown in Figure 3a $[6,16]$. A recompression shock is developed from the slope of the shear layer. From the step mixer, a $2 \mathrm{~mm}$ thick and $6 \mathrm{~mm}$ long block is extended from the step wall. There is a cavity under the extended block. The expansion fan and the shear layer can also be seen in Figure $3 \mathrm{~b}$. Compared with the step mixer in Figure 3a, the position where the recompression shock collides with the upper wall moves downstream in Figure 3b. This movement length is about $6 \mathrm{~mm}$, which coincides with the length of the extended block. The extended block plays a role in extending the recirculation region and has little effect on the flow structure development. To provide the main flow into the recirculation region, several holes were perforated into the extended block surface. In Figure 3c, inflow air through the holes seems to be observed under the extended block. This inflow air stirs the recirculation region, leading to a fluctuating shear layer; weak shocks can be seen from the shear layer [16]. To increase the inflow air into the recirculation region, a slot was made in the extended block, as shown in Figure 3d. Compared with the flow structures around the shear layer in Figure 3c, weak shocks are clearly observed, and a recompression shock is created far from the shear layer surface in Figure 3d. 

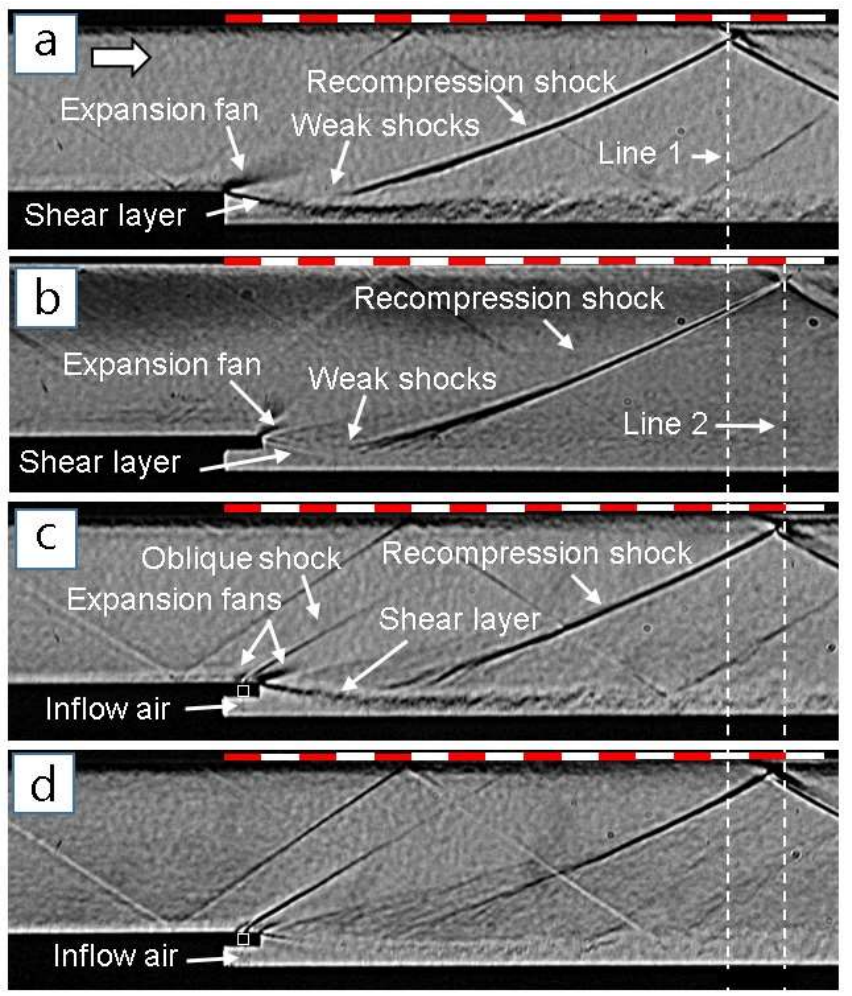

Figure 3. Flow field of various mixer models: (a) step mixer, (b) step mixer with an extended block, (c) vent circle mixer, and (d) vent slot mixer.

Figure 4 shows a flow field comparison of the three mixer models for $J=1.6$. The hydrogen gas injectant was not burnt in the mixing test for safety reasons, and thus the momentum flux ratio was very low (the equivalence ratio (ER) was about 0.02 ). The global equivalence ratio was calculated from the ratio of the actual hydrogen-air to the ratio (hydrogen-air) for a stoichiometric process. The step mixer was basically used to compare the vent mixer models in terms of their flow structure. Firstly, for the parallel injection, the injection hardly disturbs the downstream flow structures. The injection thickens the shear layer, and this affects the starting point of the recompression shock, as shown in Figure $4 \mathrm{~d}$. For the VCM, the recompression shock around the shear layer is changed from the single bold line (Figure $4 \mathrm{~b}$ ) to the Mach waves in Figure 4e. The VSM shows that the parallel injection slightly affects the shear layer increase in Figure 4f. The flow field of the VSM is similar to that of the VCM. The normal 1 injection is close to the step wall in Figure 4g. The injection interacts with the flow structures around the step corner. The downstream shear layer is, thus, fluctuating and the recompression shock shows a sinusoidal movement around the shear layer. The injection rate is very low; a bow shock is faintly seen at the step corner in Figure 4g. For the VCM, the normal 1 injection conflicts against the extended block and then runs downstream. Therefore, the normal 1 injection shows a similar flow field to the parallel injection, as shown in Figure 4e,h. For the VSM, on the other hand, the recompression shock near the shear layer disappears in Figure 4i. It is considered that the inflow air through the slot actively scatters the injection downstream. The normal 2 injector is located behind the extended block of both vent mixers. For the step mixer, the injection penetrates through the slope of the shear layer in Figure 4j. A bow shock is generated ahead of the injection, inducing fluctuation of the downstream shear layer. However, for both the vent mixers, the bow shock of the injection is not clearly observed in Figure $4 k, 1$. This is because the weak bow shock is overlapped with the expansion fan at the edge of the extended block. The bow shock scatters the downstream shear layer, similar to the step mixer case in Figure 4g. Furthermore, the normal 2 injection has little effect on the shear layer growth when considering the recompression shock shape. The shear layer growth behind the mixers weakens the recompression shock development around the shear layer surface. 

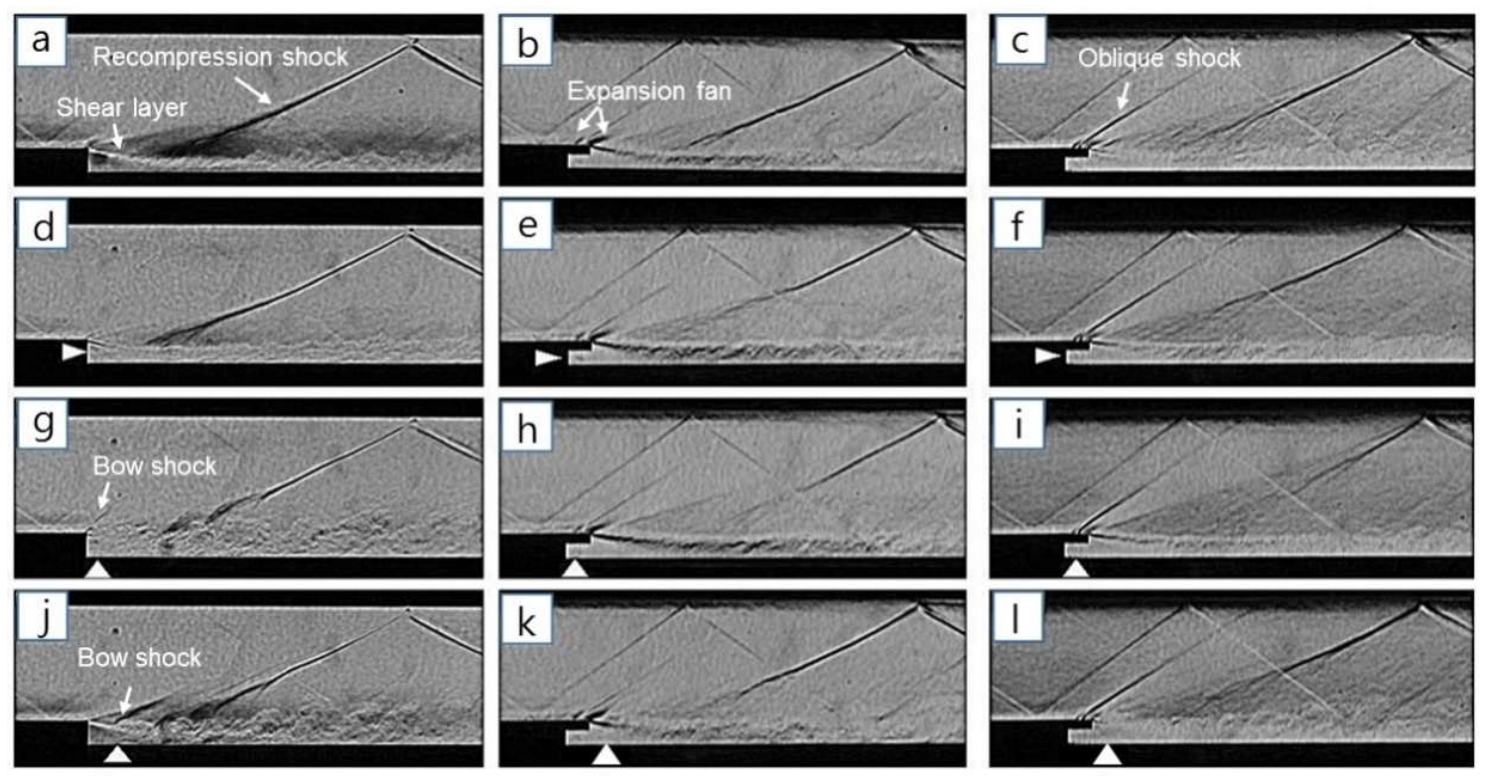

Figure 4. Flow field characteristics with regard to the injection locations for $J=1.6$ : step mixer $(\mathbf{a}, \mathbf{d}, \mathbf{g}, \mathbf{j})$, vent circle mixer $(\mathbf{b}, \mathbf{e}, \mathbf{h}, \mathbf{k})$, and vent slot mixer $(\mathbf{c}, \mathbf{f}, \mathbf{i}, \mathbf{l})$.

With the Schlieren images, the hydrogen gas concentration was measured from span 1 (S1) and span 2 (S2). For the parallel injection, the step mixer shows a peak value at $Z=0$ and lower values toward the side direction in Figure 5a. This distribution pattern is sustained in the downstream region (S2). However, both the vent mixers have an even distribution with a high concentration value around the center region along span 1 . The concentration around the side region is also relatively high in comparison with that of the step mixer. The inflow air through the slot or the holes disturbs the parallel injection, and this contributes to enhancing the injectant dispersion downstream. For the normal 1 injection, the hydrogen concentration of the step mixer decreases by half of the proportion of the parallel injection case. This is because most of the injectant is thrown out to the main flow and not held in the shear layer, as shown in Figure 5b. Meanwhile, for both the vent mixers, the normal injection is obstructed by the extended block. Therefore, much injectant can be held in the shear layer and its concentration distribution depicts a highly flat pattern, as shown in Figure 5b. For the normal 2 injection, three mixer models show the same distribution pattern, as shown in Figure 5c. For the step mixer, the different normal injector positions have little effect on the concentration distribution, as shown in Figure 5 b,c. Furthermore, the normal 2 injection is hardly affected by the inflow air of both the vent mixers. From the hydrogen concentration data, as a result, it is considered that the relationship between the injection position and the slot (or the holes) position plays a significant role in the mixing process in the shear layer.

Figure 6a shows the effect of the PJ used as the hot source in the flow field. Without the PJ injection, the pressure drops sharply in the expansion region behind the vent mixer and the pressure recovers through the recompression shock. The downstream pressure behind the PJ torch shows a large up and down pattern, because the recompression shock also moves toward the downstream region. When the recompression shock collides against the upper wall, the boundary layer is separated, leading to expansion fan development and the reflected recompression shock toward the lower wall in Figure 6 b. The reflected recompression shock moves continuously toward the lower wall until it disappears downstream. This kind of flow structure, induced by the recompression shock, induces the pressure variation around the boundary layer in Figure 6a. When the PJ, which is the hot jet plume in Figure $6 \mathrm{~b}$, is injected, the downstream pressure increases and a pressure fluctuation, due to the recompression shock and a bow shock, can be seen in Figure $6 a, b$. To sum this up, the PJ has little effect on the upstream pressure, and the downstream pressure behind the PJ torch is mainly affected by the recompression shock. 


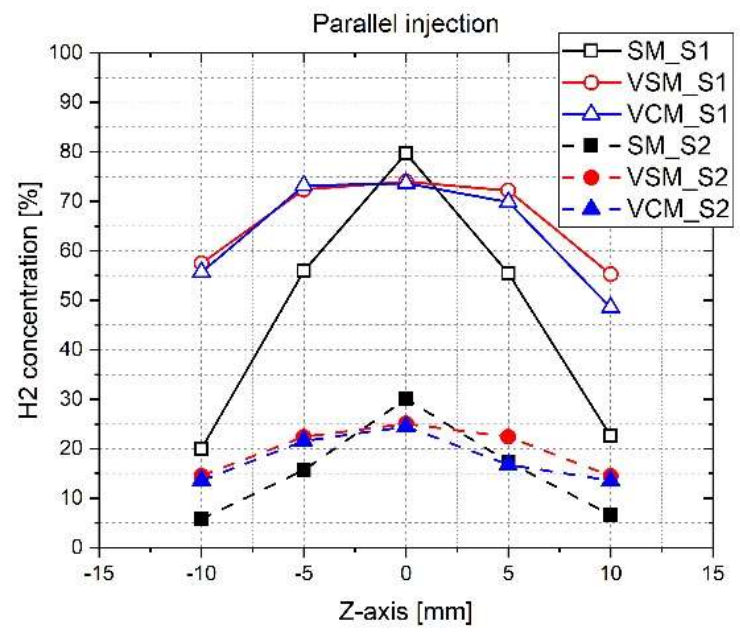

(a)

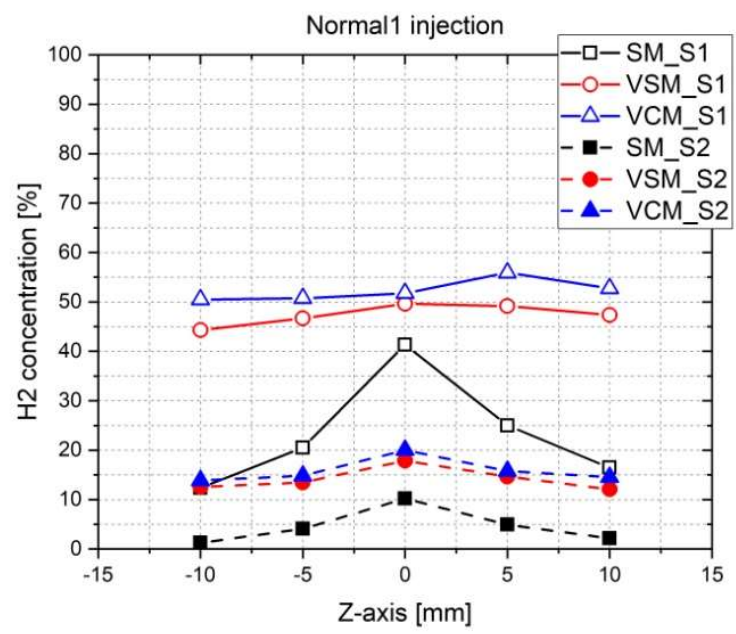

(b)

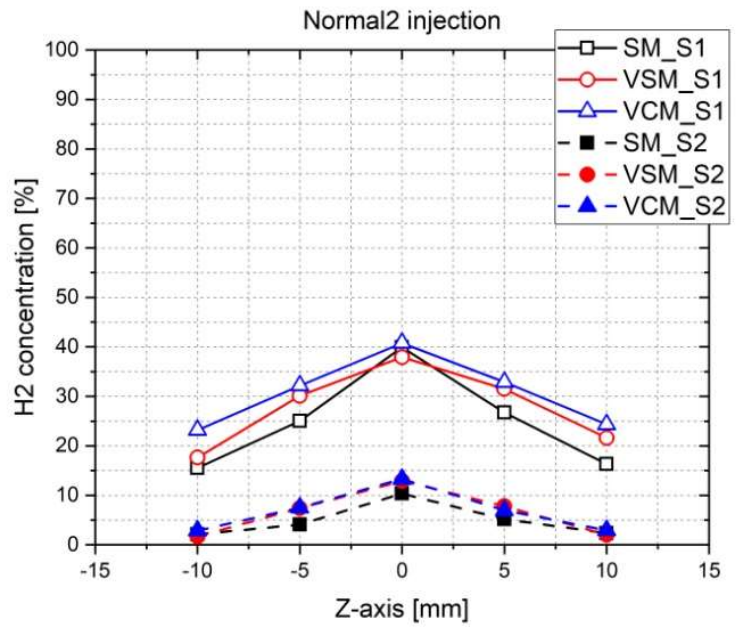

(c)

Figure 5. Hydrogen gas concentration distribution for injection locations: (a) parallel injection, (b) normal 1 injection, and (c) normal 2 injection (SM-step mixer, VSM-vent slot mixer, VCM—vent circle mixer, S1-span 1, S2-span 2). 


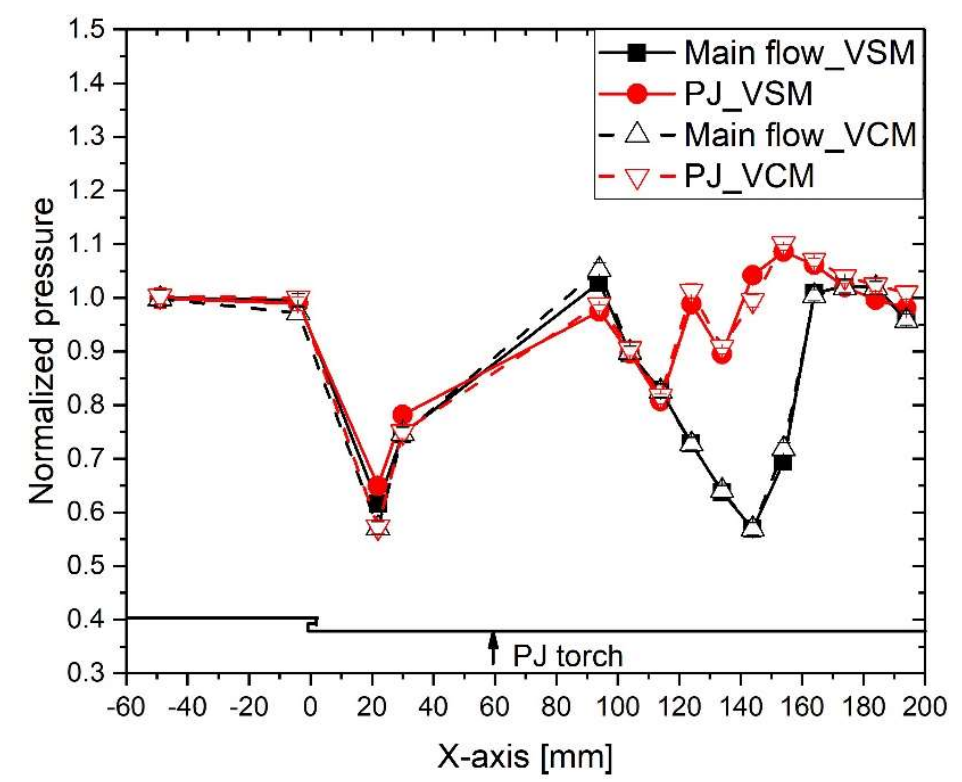

(a) Pressure distribution

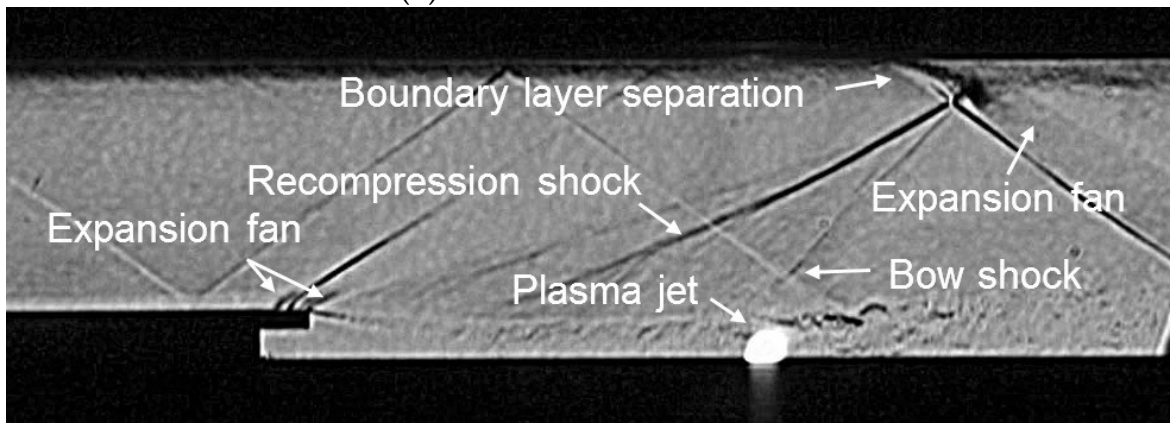

(b) Flow structures around the plasma jet

Figure 6. Pressure distribution and flow structure by the effect of the plasma jet: VSM-vent slot mixer, VCM—vent circle mixer, PJ—plasma jet.

The isolator of the duct-type combustor is designed using Billig's formula, and the pressure ratio $\left(P_{\text {out }} / P_{\text {in }}\right)$ is about 2:1 in our case. A pressure ratio above 2:1 indicates that the flow is thermally choked, as shown in Figure 7 . The thermal choking means that, for supersonic flow, heat addition causes the decrease of the Mach number towards unity [17]. For ER $=0.02$, the combustion pressure distributions of the VSM and the VCM show the same pattern, which matches the hydrogen concentration distribution in the mixing test, shown in Figure 5a. As the ER increases, the VSM has a higher combustion pressure than the VCM. The combustion can be held in the hot region for forced ignition under the cold flow condition. For our case, hydrogen was burned in the PJ and not ignited in the cold main flow. In this sense, for the same ER, the VCM scatters the hydrogen more toward the span-wise direction so that it is not burned by the PJ compared with the VSM. For ER $=0.02$, the combustion is very weak, so the upstream pressure of the PJ is not affected, and the recompression shock can be still seen, as shown in Figure 8a,b. For ER $=0.03$, the combustion becomes stronger and induces boundary layer separation around both the vent mixers, as shown in Figure 8c,d. The combustible region is restricted around the lower wall with the hot source due to the cold main flow. For this reason, boundary layer separation first develops from the lower wall and then the upper boundary layer separation follows, which contributes to the asymmetric oblique shock train. The pressure ports in the isolator are embedded on the upper wall. The combustion pressure of the VSM is higher than that of the VCM, as shown in Figure 7. The oblique shock train of the VSM is strong and the upper boundary layer separation goes close to the isolator outlet, as can be seen in Figure 8. For ER $=0.04$, the VSM shows the unstart condition. The pressure increases in the nozzle outlet and all pressure ratios exceed 2:1, as 
seen in Figure 7. Under the unstart condition, the shock train intrudes into the nozzle exit and the downstream flow becomes subsonic. However, in the suction-type test facility, the main flow recovers to supersonic flow due to the vacuum suction, which comes to be the unstart again. This process is quickly repeated, as shown in Figure 8e,e $e^{\prime}$. The oblique shock train goes toward the nozzle exit, as shown in Figure 8e. After the shock train intrudes into the nozzle, the lambda shock train can be seen, as shown in Figure 8 $\mathrm{e}^{\prime}$. For the VCM, the shock train displays upstream and downstream movements in the isolator and does not go into the nozzle, as shown in Figure 8f, $\mathrm{f}^{\prime}$.

Parallel injection

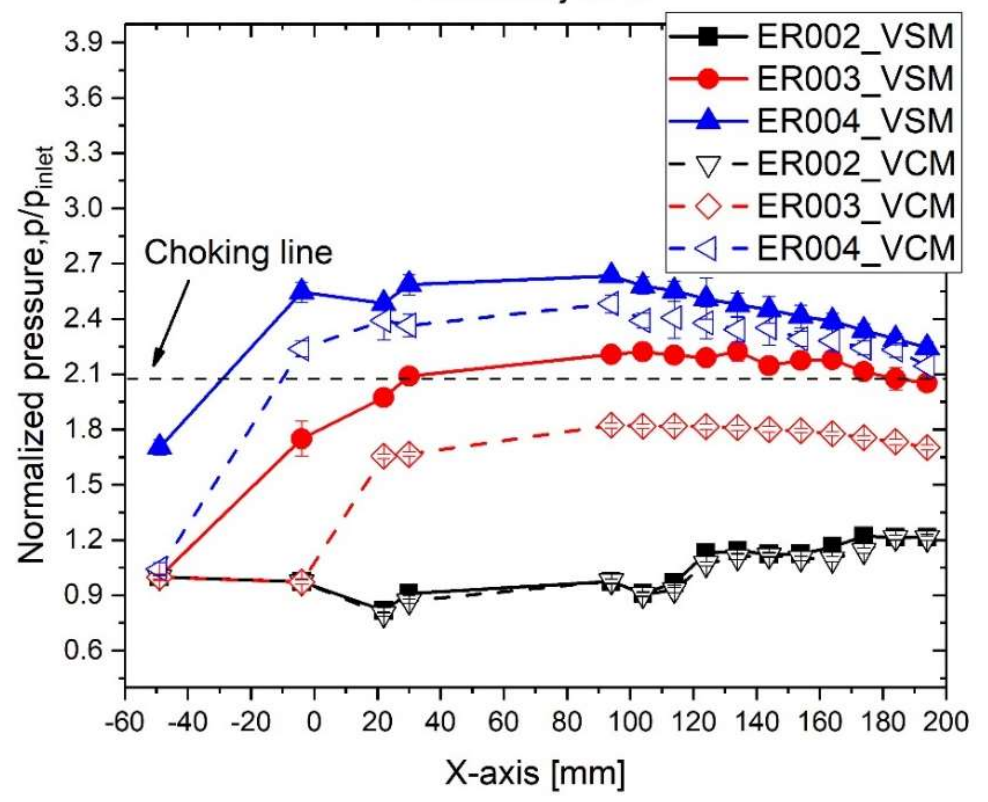

Figure 7. Combustion pressure distribution of the parallel injection for ER rise: VCM-vent circle mixer, VSM—vent slot mixer, ER—equivalence ratio.
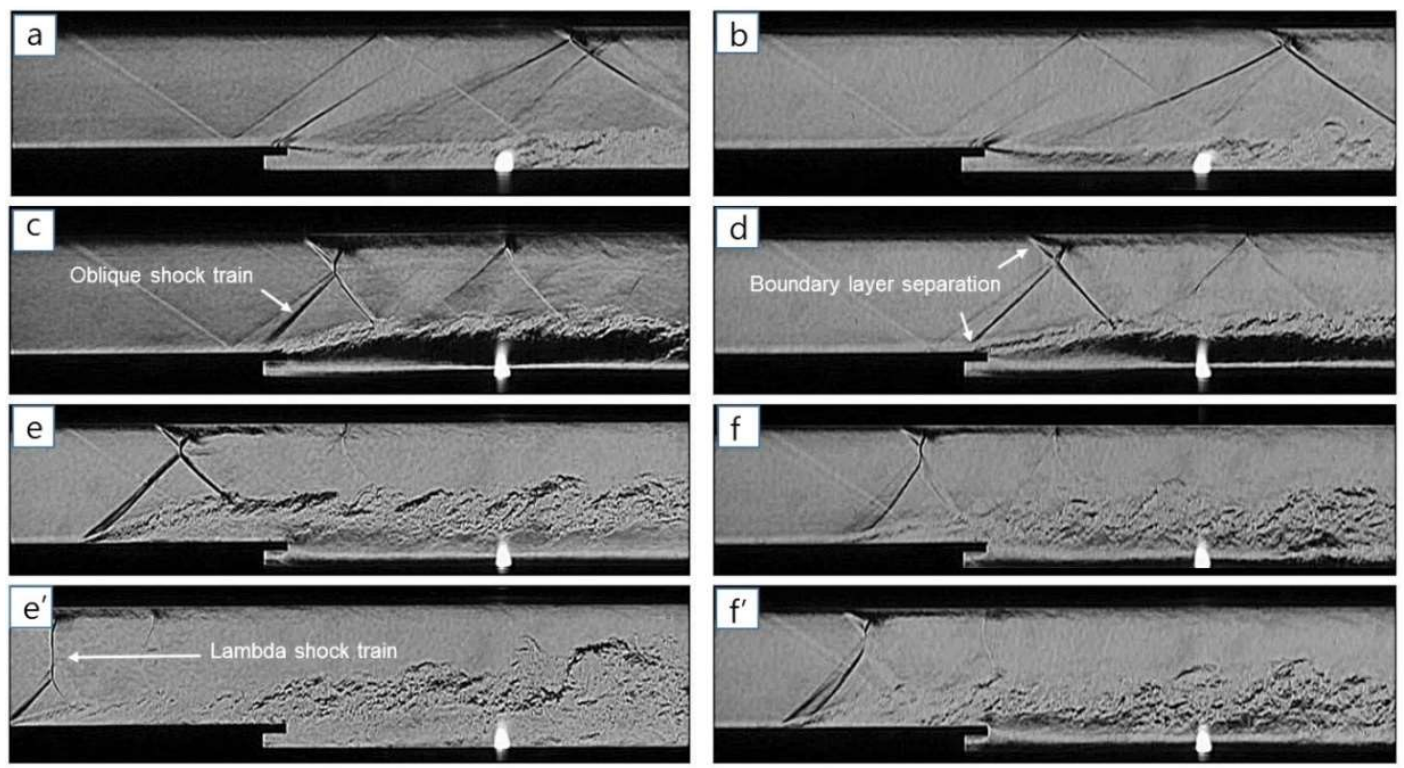

Figure 8. Flow structure transition of the parallel injection for ER rise: vent slot mixer $\left(\mathbf{a}, \mathbf{c}, \mathbf{e}, \mathbf{e}^{\prime}\right)$ and vent circle mixer $\left(\mathbf{b}, \mathbf{d}, \mathbf{f}, \mathbf{f}^{\prime}\right)$.

In the case of the normal 1 injection, both the vent mixers show similar combustion pressure patterns, as seen in Figure 9. For ER $=0.02$ and 0.03, the downstream combustion pressures are low and are affected by the recompression shock. In Figure 10a-d, the shock structures, such as the 
recompression shock and the bow shock, can still be seen around the upper wall region and the four figures show little difference in the flow fields. For ER $=0.04$, the flow is thermally choked in the combustor and the shock train exists in the isolator for both the vent mixers. This can be seen in Figure 10e,f. Although the normal 1 injection results in good mixing performance, as seen in Figure 5b, the amount of hydrogen supplied into the PJ is reduced by the wide dispersion, contributing to the weak combustion. However, as the combustion is strong enough to affect the side region, the combustion pressure rises sharply.

\section{Normal 1 injection}

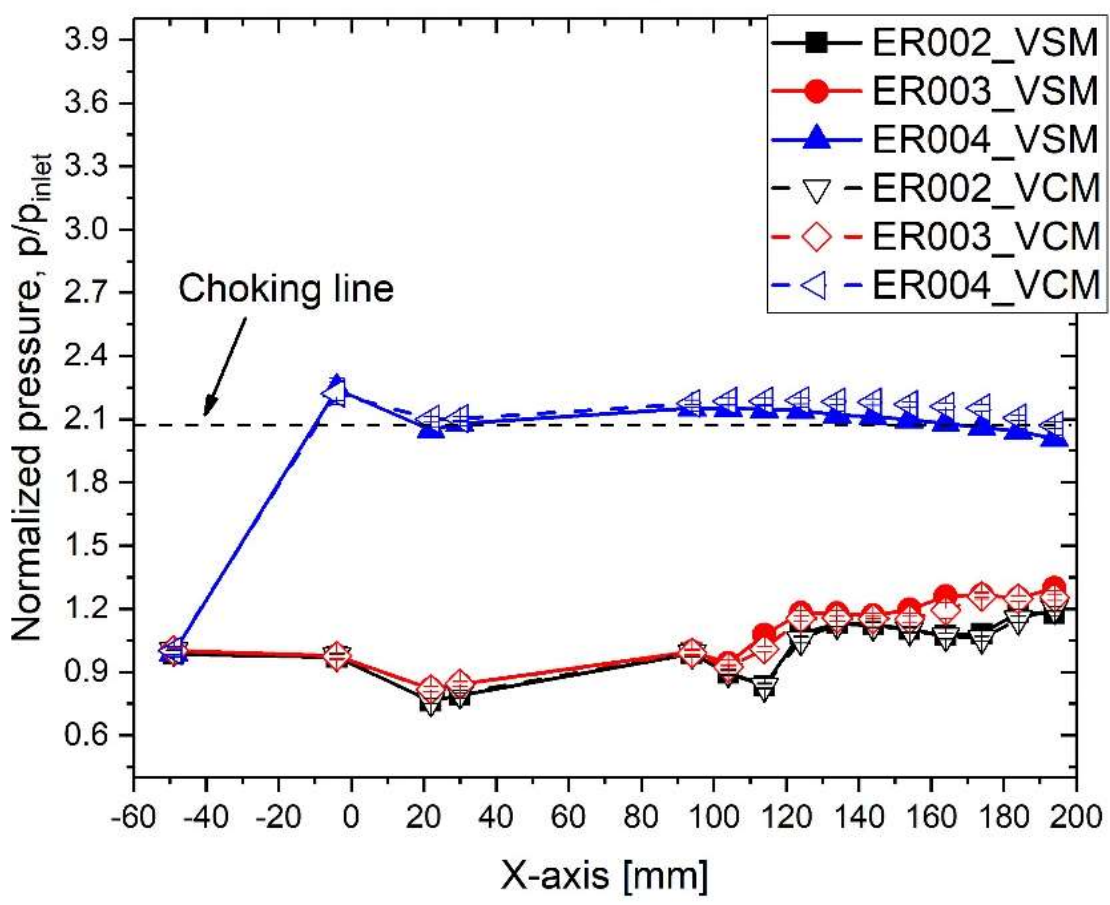

Figure 9. Combustion pressure distribution of the normal 1 injection for ER rise: VCM-vent circle mixer, VSM—vent slot mixer, ER—equivalence ratio.
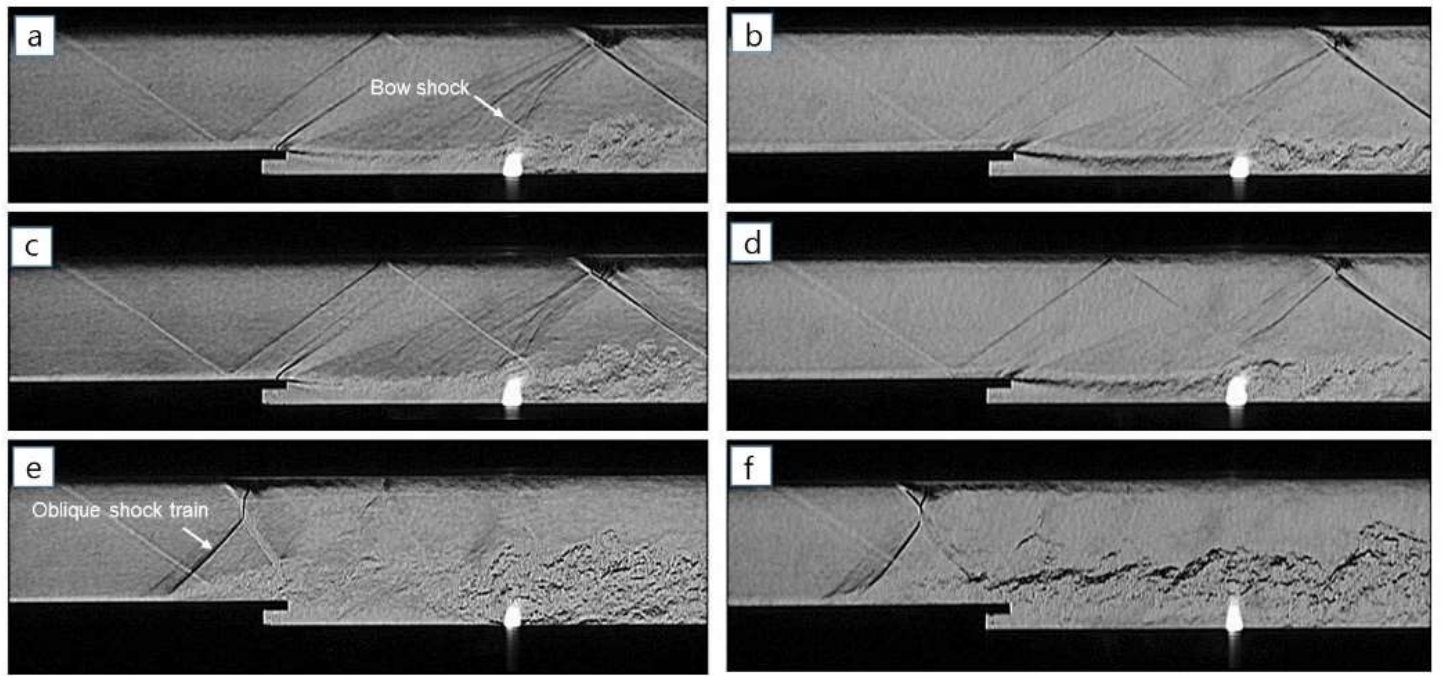

Figure 10. Flow structure transition of the normal 1 injection for ER rise: vent slot mixer $(\mathbf{a}, \mathbf{c}, \mathbf{e})$ and vent circle mixer $(\mathbf{b}, \mathbf{d}, \mathbf{f})$.

In Figure 11, for the normal 2 injection, there is no thermal choking for all ER ranges. For ER $=0.02$, both the vent mixers show the same combustion pressure pattern. For ER $=0.03$, the VSM is superior to 
the VCM in the downstream combustion pressure. In Figure 12, the recompression shock is observed in all figures, and the downstream jet plume fluctuates intensely according to the ER increase. The span-wise combustion pressure measured from span three is displayed in Figure 13. The PJ without combustion shows a flat pressure distribution. For ER $=0.2$ and 0.3 , the weak combustion has a somewhat high pressure in the center region relative to the surrounding pressures. This is considered to be owing to combustion only occurring weakly in the PJ. As mentioned earlier, the normal 2 injection supplies most of the hydrogen gas into the cold main flow, so it will not be burned by combustion. Because of this, combustion occurs just in the jet plume, due to the small quantity of hydrogen gas. As the injection rate increases, the span-wise combustion pressure rises evenly.

\section{Normal 2 injection}

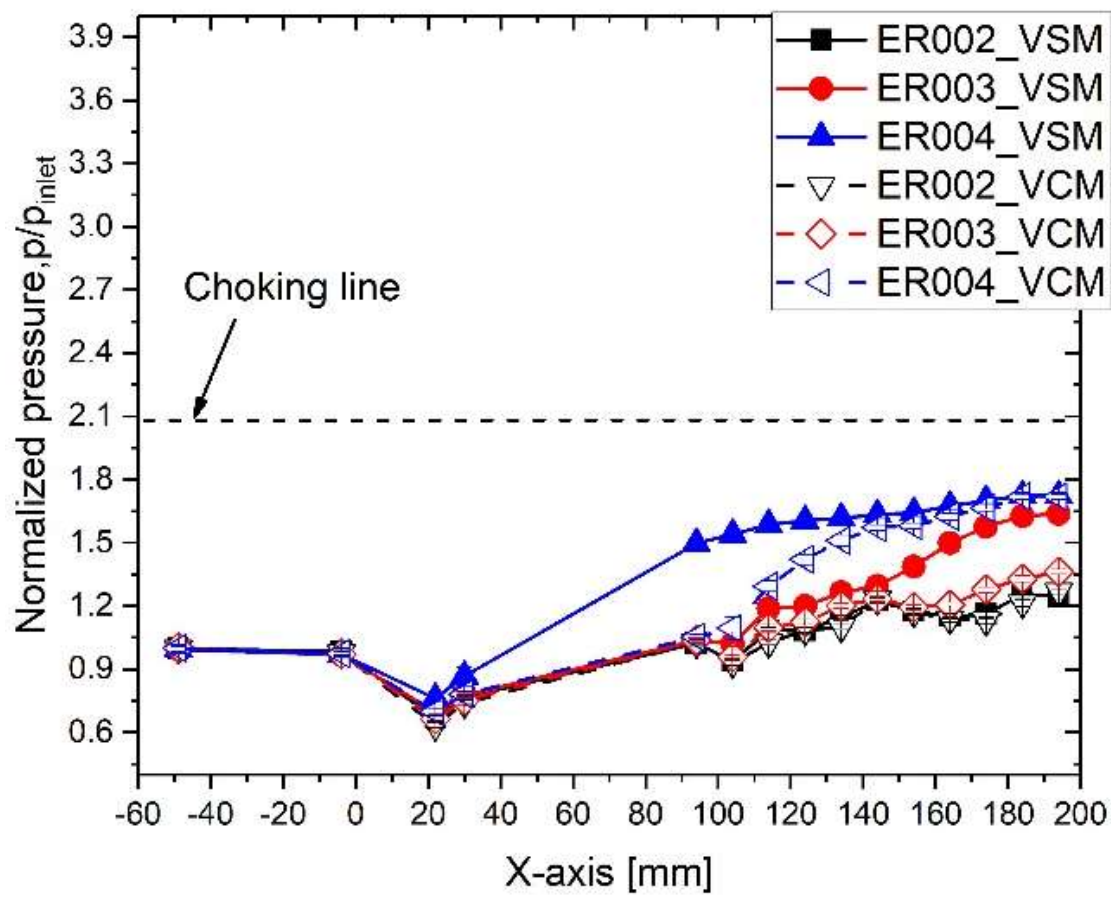

Figure 11. Combustion pressure distribution of the normal 2 injection for ER rise: VCM-vent circle mixer, VSM-vent slot mixer, ER—equivalence ratio.
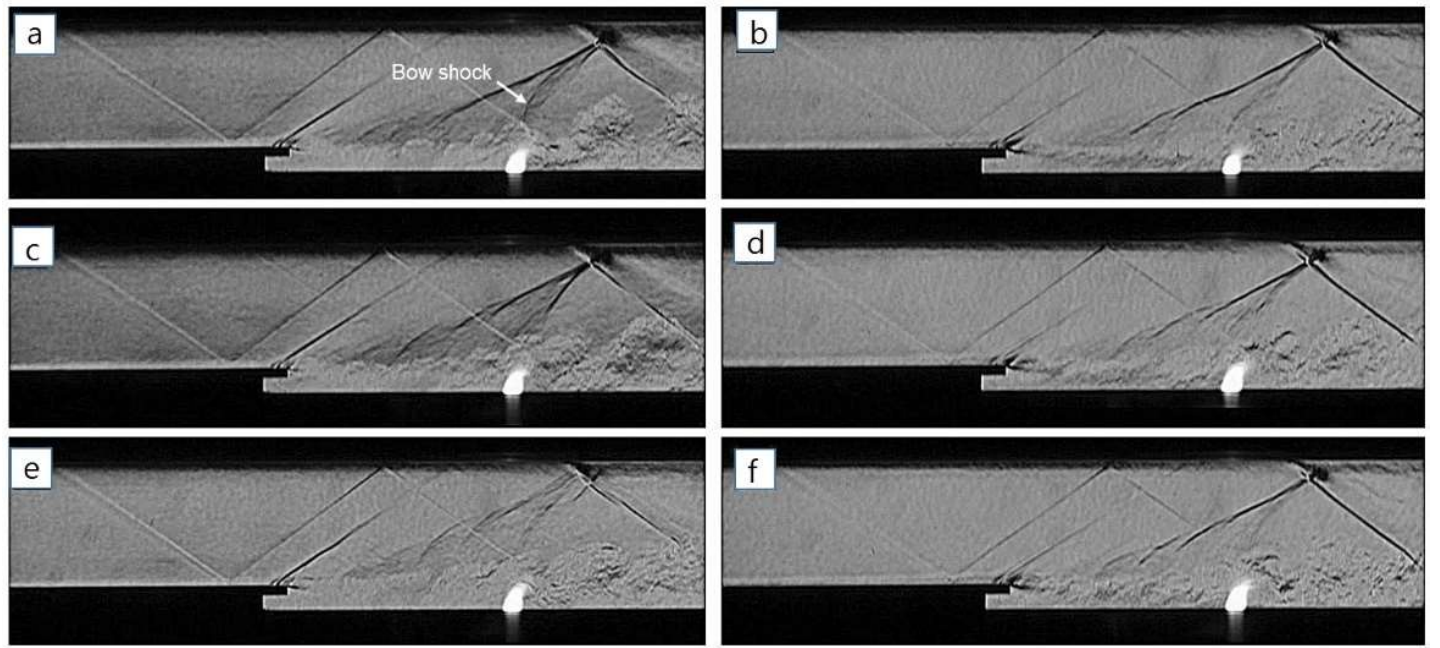

Figure 12. Flow structure transition of the normal 2 injection for ER rise: vent slot mixer $(\mathbf{a}, \mathbf{c}, \mathbf{e})$ and vent circle mixer $(\mathbf{b}, \mathbf{d}, \mathbf{f})$. 


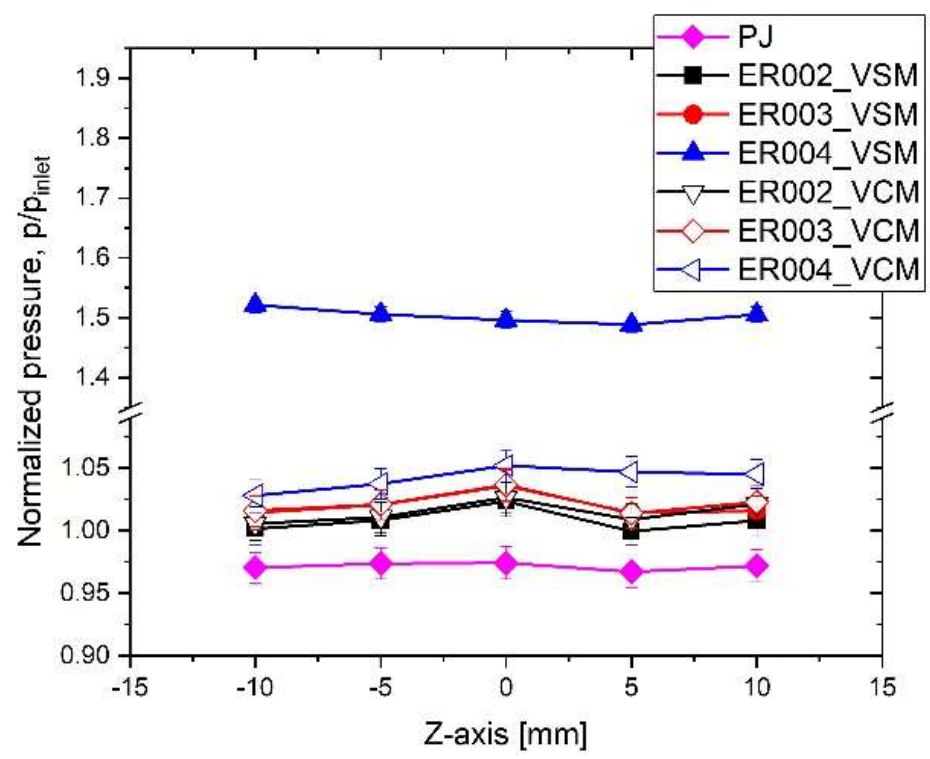

Figure 13. Span-wise pressure distribution comparison: VCM-vent circle mixer, VSM-vent slot mixer, ER-equivalence ratio.

In order to compare the overall combustion performance, each combustion pressure difference between the combustion pressure $\left(P_{c o m}\right)$ and the pressure without combustion $\left(P_{P J}\right)$ is summarized and normalized by the total pressure $\left(P_{\text {total }}\right)$. The combustion pressure increment $(\Delta P)$ is evaluated by:

$$
\Delta \mathrm{P}=\frac{\sum\left(P_{\text {com }}-P_{P J}\right)}{P_{\text {total }}}
$$

If the combustion pressure increment exceeds unity in Figure 14, the combustor enters the thermal choking condition and the shock train is developed in the isolator. In the one-dimensional Rayleigh flow condition [17], the heat addition (or equivalence ratio) required to choke the flow is dependent on the inflow total temperature. For instance, if the inflow total temperature is about $1047 \mathrm{~K}$, which corresponds to a flight Mach number of 4 [18], the equivalence ratio of hydrogen gas for choking at the constant duct exit is about $0.1[19,20]$. In our case, the inflow air is not hot enough to be combustible but instead is ambient air, so the equivalence ratio for choking the flow is about 0.03 for the inflow total temperature of $296 \mathrm{~K}$. In this sense, for $E R=0.03$, thermal choking begins in the case of the parallel injection for the three mixer models. This indicates that the hydrogen is mostly burned in the combustor and the combustion efficiency is high. In the mixing test, the remaining hydrogen volume of the normal 1 injection of the two vent mixers is secondary to the parallel injection in Figure 3 . Therefore, for ER $=0.04$, the combustion pressure increments of the normal 1 injection for the two vent mixers go beyond unity, as shown in Figure 12. All injection cases show thermal choking in the combustor for $\mathrm{ER}=0.06$. 


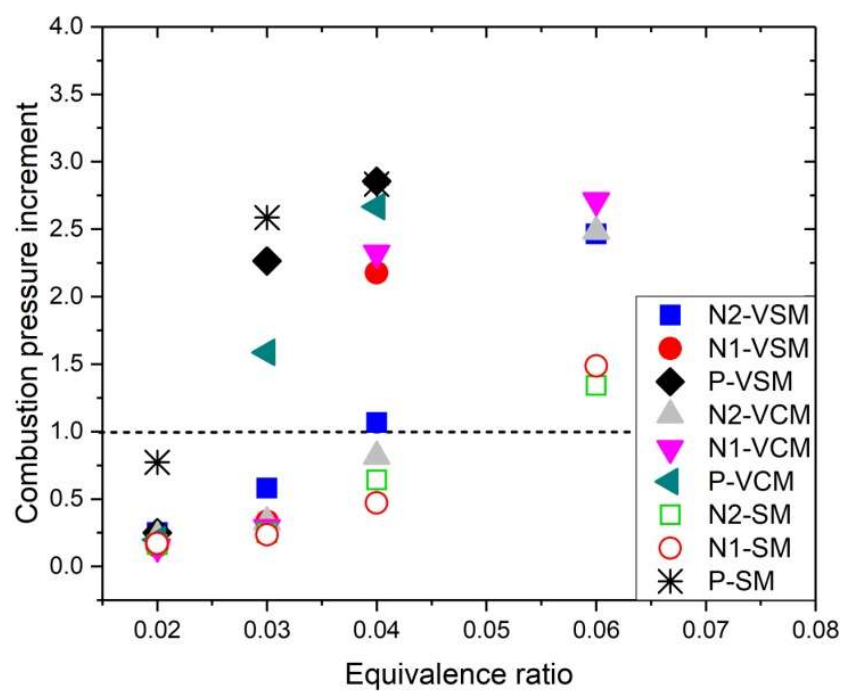

Figure 14. Combustion performance comparison: $\mathrm{P}$-parallel injection, N1—normal 1 injection, N2—normal 2 injection, SM—step mixer, VSM—vent slot mixer, VCM—vent circle mixer.

\section{Conclusions}

This work was carried out to study the performance of vent mixer models in a laboratory-scaled supersonic combustor facility, with forced ignition by a plasma jet torch performed with the cold main flow.

In the mixing test, the inflow air through the slot or circular holes of the mixers enhances the mixing characteristics, particularly span-wise dispersion, while the injectant is emitted in the recirculation region. In other words, the mixers are effective at dispersing the hydrogen-air mixture by direct interaction between the inflow air and the injection. On the other hand, injection out of the roof-plate of the mixer is little affected by the inflow air through the slot or circular holes of the mixers. Furthermore, the mixing pattern shows similar performance irrespective of hole shape, such as a slot or circular hole, on the roof-plate of the mixer.

Under the unheated main flow condition, the combustion is sensitive to the hydrogen flow rate supplied to the plasma jet in the small-scaled combustor. Although the fuel-air mixture is widely dispersed in the shear layer or the recirculation region, it is difficult to ignite the fuel-air mixture without the heat source. First of all, thermal choking occurs for the parallel injection for ER $=0.03$ regardless of the mixer models, compared with the normal 1 and normal 2 injections. For the parallel injection, although the mixing performances of the VSM and the VCM are similar to each other, thermal choking is observed earlier for the VSM than the VCM. For the normal 1 injection, both the vent mixers show similar mixing and combustion performances. The normal 2 injection has the poorest combustion performance compared with the other injection cases, and the VSM is slightly superior to the VCM in terms of the combustion pressure rise. The flow is easily thermally choked for lower equivalence ratios due to the low total temperature of the main flow. In this sense, particularly for the small combustor, it is considered that the subtle difference between fuel-air mixture rates toward the plasma jet leads to a large difference in the combustion performance.

Author Contributions: Conceptualization, C.H.K.; Methodology, C.H.K.; Software, C.H.K.; Validation, C.H.K.; Formal Analysis, C.H.K.; Investigation, C.H.K.; Data Curation, C.H.K.; Writing-Original Draft Preparation, C.H.K.; Writing-Review \& Editing, C.H.K. and I.S.J.; Supervision, I.S.J.; Project Administration, I.S.J.

Funding: This research received no external funding.

Conflicts of Interest: The authors declare no conflict of interest. 


\section{References}

1. Sullins, G.A. Demonstration of mode transition in a scramjet combustor. J. Propuls. Power 1993, 9, 515-520. [CrossRef]

2. Daines, R.; Seagal, C. Combined rocket and airbreathing propulsion systems for space-launch applications. J. Propuls. Power 1998, 14, 605-612. [CrossRef]

3. Billig, F.S. Research on supersonic combustion. J. Propuls. Power 1993, 9, 499-514. [CrossRef]

4. Seiner, J.M.; Dash, S.M.; Kenzakowski, D.C. Historical survey on enhanced mixing in scramjet engines. J. Propuls. Power 2001, 17, 1273-1286. [CrossRef]

5. Gruber, M.R.; Baurle, R.A.; Mathur, T.; Hsu, K.-Y. Fundamental studies of cavity-based flameholder concepts for supersonic combustors. J. Propuls. Power 2001, 17, 146-153. [CrossRef]

6. Roshko, A.; Thomke, G.J. Observations of turbulent reattachment behind an axisymmetric downstream-facing step in supersonic Flow. AIAA J. 1996, 4, 975-980. [CrossRef]

7. Kim, C.-H.; Jeung, I.-S.; Choi, B.; Kouchi, T.; Takita, K.; Masuya, G. Effect of fuel injection location on a plasma jet assisted combustion with a backward-facing step. Proc. Combust. Inst. 2011, 33, 2375-2382. [CrossRef]

8. Tang, P.K.; Sirignana, W.A. Theory of a generalized Helmholtz resonator. J. Sound Vib. 1973, 26, $247-262$. [CrossRef]

9. Doster, J.C.; King, P.I.; Gruber, M.R.; Carter, C.D.; Ryan, M.D.; Hsu, K.-Y. In-stream hypermixer fueling pylons in supersonic flow. J. Propuls. Power 2009, 25, 885-901. [CrossRef]

10. Kim, C.-H.; Jeung, I.-S.; Choi, B.; Kouchi, T.; Masuya, G. Flowfield characteristics of a hypermixer interacting with transverse injection in supersonic flow. AIAA J. 2012, 50, 1742-1753. [CrossRef]

11. Kim, C.-H.; Sung, K.; Jeung, I.-S.; Choi, B.; Kouchi, T.; Masuya, G. Flowfield characteristics on a vent slot mixer in supersonic flow. Shock Waves 2010, 20, 559-569. [CrossRef]

12. Kim, C.-H.; Jeung, I.-S. Mixing characteristics of vent slot mixer in supersonic flow. Aerosp. Sci. Technol. 2016, 49, 250-258. [CrossRef]

13. Thakur, A.; Segal, C. Concentration distribution in a supersonic flow recirculation region. J. Propuls. Power 2008, 24, 64-73. [CrossRef]

14. Masuya, G.; Takita, K.; Takahashi, K.; Takatori, F.; Ohzeki, K. Effect of airstream Mach number on H2/N2 plasma igniter. J. Propuls. Power 2002, 18, 679-685. [CrossRef]

15. Takita, K.; Murakami, K.; Nakane, H.; Masuya, G. A Novel design of a plasma jet torch igniter in a scramjet combustor. Proc. Combust. Inst. 2005, 30, 2843-2849. [CrossRef]

16. Papamoschou, D. Structure of the compressible turbulent shear layer. AIAA J. 1991, 29, 680-681. [CrossRef]

17. Anderson, J.D., Jr. Modern Compressible Flow with Historical Perspective, 2nd ed.; McGraw Hill: New York, NY, USA, 1990; pp. 77-85.

18. Evvard, J.C.; Marcus, L.R. Achievement of Continuous Wall Curvature in Design of Two-Dimensional Symmetric Supersonic Nozzles; No. NACA-TN-2616; National Aeronautics and Space Administration: Washington, DC, USA, 1952.

19. Bonanos, A.M.; Schetz, J.A.; O’Brien, W.F.; Goyne, C.P. Dual-Mode Combustion Experiments with an Integrated Aeroramp- Injector/Plasma-Torch Igniter. J. Propuls. Power 2005, 24, 267-273. [CrossRef]

20. Le, B.D.; Goyne, C.P.; Krauss, R.H.; McDaniel, J.C. Experimental Study of a Dual-Mode Scramjet Isolator. J. Propuls. Power 2008, 24, 1050-1057. [CrossRef]

(C) 2019 by the authors. Licensee MDPI, Basel, Switzerland. This article is an open access article distributed under the terms and conditions of the Creative Commons Attribution (CC BY) license (http://creativecommons.org/licenses/by/4.0/). 